\title{
“MACHISTA, RACISTAS NÃO PASSARÃO” - UMA ETNOGRAFIA NA MARCHA CONTRA O ESTUPRO EM PORTO ALEGRE
}

\author{
Evandra Gonçalves Cristina ${ }^{1}$
}

RESUMO: O texto visa refletir sobre a interseccionalidade de raça e género no contexto da marcha, em Porto Alegre, denominada "Por TODAS ELAS, realizada no dia 1 de Junho de 2016, a partir das palavras de ordem, imagens e buscar os significados a partir da literatura da área constitui-se como objetivo desse exercício etnográfico. Pois a necessidade da interseção entre a categoria de género e raça se torna fundamental para fazer frente a demanda social.

Palavras-chave: Interseccionalidade. Etnografia. Género. Raça.

\section{"MACHISTA, RACISTAS WILL NOT PASS" - AN ETHNOGRAPHY ON THE MARCH AGAINST THE RAVEN IN PORTO ALEGRE}

\begin{abstract}
The text aims to reflect on the intersectionality of race and gender in the context of the march, in Porto Alegre, called "For ALL ELAS, held on June 1, 2016, from the slogans, images and search for meanings to from the area literature constitutes the objective of this ethnographic exercise. For the necessity of the intersection between the category of gender and race becomes fundamental to face the social demand.
\end{abstract}

Key-words: Intersectionality. Ethnography. Genre. Breed.

\section{A PRIMEIRA ESTRATÉGIA ETNOGRÁFICA}

A agência de comunicação $\mathrm{BBC}$, do Reino Unido (entre diversos meios de comunicação internacional, Canadá, Inglaterra, Índia, Austrália, Estados Unidos e em Israel) afirmou no noticiário:

O vídeo nas redes sociais chocou o Brasil, mas, antes de seu autor ter a conta bloqueada, foi largamente compartilhado com comentários misógenos" referindo ao caso do estupro coletivo acorrido no Rio de Janeiro - Brasil no mês de Maio de 2016. A notícia da adolescente de 16 anos que foi estuprada por mais de 30 homens e teve as imagens da violência publicadas nas redes sociais, (http://noticias.r7.com/rio-dejaneiro/estupro-coletivo-no-rio-ganha-destaque-na-imprensa-internacional-03062016, consultada em 04/06/206).

Nas redes sociais diversos grupos de mulheres manifestaram o repudio ao ocorrido e diversas manifestações ocorreram em diferentes Estados do Brasil. Foi por meio das redes 
sociais que recebi o convite para um evento intitulado "Por TODAS ELAS" em Porto Alegre. Por ser nova na cidade e não conhecendo, além do perímetro de onde fica a minha residência, tive receio em ir sozinha na marcha, porém a curiosidade e vontade não me faltaram. Falo em curiosidade, isto por sair de uma cidade pequena, sem grandes hábitos de manifestações, para uma cidade totalmente oposta.

A partir de um convite por uma amiga, decidi participar na marcha em Porto Alegre, denominada "Por TODAS ELAS - Porto Alegre - RS, realizada no dia 1 de Junho de 2016, onde o combinado foi de irmos juntas. A semelhança da minha e de muitas mulheres, a indignação do povo, resultou na luta para que pudesse ser ouvido a voz delas, na sociedade, onde há uma maior incidência de violência com base no género sobre as mulheres.

Participei desse momento - primeiro por ser mulher; segundo por ser uma marcha pacífica; e terceiro por ser a minha primeira experiência em manifestação do tipo com um diferencial, num contexto social onde sou "uma estranha".

Seria um momento histórico! A marcha estava prevista para às $17 \mathrm{~h}$, com a concentração inicial na Esquina Democrática. Chegamos cedo no local e já se via muitos cartazes erguidos e alguma concentração de pessoas. Estavam presente pessoas das mais diversas correntes, partidos, coletivos e vertente, na sua grande maioria mulheres jovens e poucos homens que na maioria acompanhavam suas companheiras.

No microfone as palavras de ordem eram o apelo pelo fim do machismo, da cultura de estupro e da violência contra a mulher e descriminação racial. Acontecia o mesmo apelo nos mais diversos cartazes erguidos. Ao mesmo tempo que grupos diversificados aproveitavam para distribuírem folhetos com o mesmo intuito.

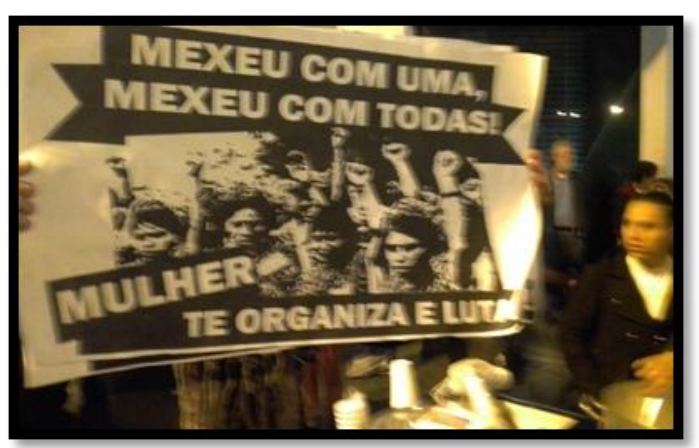

Figura 1: Mensagem no cartaz erguido na marcha. Fonte: da autora, Junho de 2016.

\footnotetext{
${ }^{1}$ Mestranda em Ciência Sociais pela UNISINOS. Licenciada em Sociologia pela Universidade de Cabo Verde. Contato: evandramor91@gmail.com
} 
Estava muito empolgada com o envolvimento das mulheres e embora na visão de algumas presentes (Brasileiras), a marcha não teve muita aderência, porém a meu ver tinha um grande número de pessoas, em comparação com a minha realidade social, diante do contexto das manifestações. Confesso que caí na tentação de comparar, pois não consegui despir das minhas pré-noções e ao mesmo tempo, estava maravilhada de poder viver aquele momento. Poder ver muitas pessoas unidas em torno de um problema, gerava uma satisfação pessoal em poder participar daquele momento. Através de fotografias e vídeos, procurei registar o momento e procurei viver aquele momento intensamente e aprender a todos os detalhes que geravam sensação de estranheza.

No microfone se ouvia palavras de ordem, que por vezes era repetida e por vezes era aclamada a quem quisesse a fazer o uso, pois aquele era o momento de desabafo e de reivindicação acima de tudo.

Foi quando quatro jovens de turbantes e negras chegarem em mim e entregaram um folheto intitulado "Quilombo raça e classe", no qual relatava o caso e a indignação do grupo, diante do caso de estupro acontecido e não deixando de falar como "no Brasil historicamente as mulheres negras lutam por reparação, pois os mais de 350 anos de escravidão se apropriaram não só das riquezas de nossa terra, mas também dos corpos..."

Quando recebi a folha, a jovem me disse: "lute sempre”! Li na hora o título e segui as quatros jovens de longe e percebi que não entregavam o folheto para todas as pessoas. Sempre escolhiam as mulheres negras.

E aquilo me chamou bastante atenção e fiquei questionando internamente qual a intenção delas. Daí comecei a olhar em volta e pude perceber que havia pouca presença de mulheres negras na marcha. Pensei tudo bem, é o que acontece no Brasil, ao menos na minha perceção, “os negros são invisíveis ou não existem”. Falo isto, de um lugar muito específico e com menos de um ano "andando" por alguns lugares do Sul do Brasil, no qual sempre essa questão me vinha a mente. Na maioria dos lugares (restaurantes, universidades, passeios e festas) sempre eu era a única negra e se tivesse mais pessoas negras era possível contá-las sem nenhum problema.

A frase da menina me chamou bastante atenção e passei a ter inúmeras inquietações e resolvi apreender o máximo das informações a partir da etnografia. De seguida, abri a minha mochila e tirei o meu caderno e comecei a tomar apontamentos. Em uma das cadeiras do curso estávamos a falar das questões raciais e questões de género e do privilégio da etnografia e pensei: "vou escrever sobre isso". 
Deparei com um cenário, onde a minha cor da pele determinou ação de outra pessoa e ao mesmo tempo demonstrando o desabafo de descontentamento e a força em querer lutar por uma sociedade onde a cor da pele deixe de ser o elemento diferenciação. Por ser mulher, negra, em um contexto de "diferenciação" diante das demais colegas com quem estávamos juntas, todas brancas. Até a menina chegar em mim e entregar o folheto a questão da cor, não era um determinante.

Porém as diversas leituras sobre a intersecionalidade vista nas aulas se fizeram presente. Diante de acontecido, procuro no texto refletir sobre a interseccionalidade de raça e género no contexto da marcha, a partir das palavras de ordem, imagens e buscar os significados a partir da literatura da área constitui-se como objetivo desse exercício etnográfico.

\section{O PRIVILÉGIO DA ETNOGRAFIA}

A etnografia seria o único método que me permitisse descrever o momento, pois ao mesmo tempo em que eu era um "corpo comum", no contexto da marcha, deixei de ser apenas um corpo, mais sim um corpo rotulado a critério dos outros. Os corpos eram demarcados pela cor e outras carateristicas, tais como turbantes e cabelo. Pois esses determinantes me enquadravam no perfil.

E como refere (STRATHERN, 2014), o fazer etnográfico quanto narrativa etnográficas são construídos sob interações reais ou imaginadas entre o olhar do pesquisador sobre o nativo e deste sobre o pesquisador. Ainda que a etnografia seja uma construção analítica dos académicos, os objetos de estudo, os nativos não o são. E sendo assim, cabe reconhecer que aquilo que proponho construir como sendo os olhares nativos, nunca dão conta da totalidade da criatividade do nativo, por ser uma "análise singular". No qual esta análise seria "parte do exercício antropológico que é reconhecer o quanto a criatividade desses povos é maior do que aquilo que pode ser compreendido por qualquer análise (STRATHERN, 2014.).

A fala da autora, me faz pensar a ponto de compreender a reação e ação daquelas meninas negras na marcha e o quanto a etnografia torna-se pertinente para captar o que realmente elas estavam propondo. Pois além de ser uma análise singular, estava diante de uma criatividade e tanta que a minha análise estaria muito longe de alcançar o propósito delas. 


\section{"NÃO VOU ME CURVAR"!}

O corpo afigura um naipe proeminente nas discussões feministas e cada vez mais temse tornado foco de atenção da produção académica, estimulando estudos orientados pelas mais diversas abordagens. Explorar as maneiras como os corpos são moldados por formas de poder e discutir como os impactos da mercantilização os fragmentam.

Atualmente as reflexões dobre sobre o corpo e corporalidade integram-se, porém, num amplo campo de discussão, ainda que manifestam o interesse por género concedendo uma atenção crescente (MOORE, 2000) e que no quotidiano é uma realidade.

E o caso que aconteceu em Rio de Janeiro uma vez mais veio reforçar essa certeza. Para além das diferenças sexuais, há outras diferenças, por isso a teórica (HARAWAY, 1995) crítica o conceito de género interna ao movimento feminista. O que no campo das ciências sociais principalmente, na reelaboração teórica de não incorporarem as exigências de prestar atenção a outras diferenças, para além da sexual, de maneira homogénea (PISCITELLI, 2008). Ainda autora fala na redefinição de novas questões, em conjunto com uma visão de igualdade e também que incluísse classe e raça.

Judith Butler pensa género como um mecanismo segundo o qual se produzem e naturalizam noções do masculino e feminino, mas também como mecanismo mediante o qual esses termos são e desnaturalizados (BUTLER, 2003).

O que por sua vez era a ideia das mulheres participantes na marcha. Gritando "não vou me curvar! Não vou me calar”. A ideia de que tinha da mulher subalterna (SPIVACK, 2010), obedecendo e cumprindo as ordens dos homens não está mais vinculadas. Porque hoje, as mulheres saem para rua, gritam palavras de ordem e ocupam diversos lugares na esfera pública. Porém há muitos desafios a ultrapassar, porém, reconhece-se que grandes passos já foram conseguidos. As mulheres já não aceitam a "dominação masculina" (BOURDIEU, 1999) de forma passiva.

A existência de múltiplos discursos de género dentro de um mesmo contexto social significa que em muitas situações um discurso que enfatiza a natureza oposicional e mutuamente exclusiva das categorias de género pode existir ao lado de outros discursos que enfatizam a natureza processual, mutável e temporária de atribuição de género (MOORE, 2000).

A autora ainda acrescenta: 
A coexistência de múltiplos discursos, contudo produz uma situação em que os diferentes discursos sobre género são hierarquicamente ordenados. O ordenamento pode ser contextual como bibliograficamente variável, e também pode estar sujeito a mudança histórica. O resultado é que alguns discursos sobredeterminam outros, e vários discursos sub-dominantes se desenvolvem em oposição aos dominantes (MOORE, 2000, p:28).

Isto porque em muitas culturas, discursos em oposições a género são hierarquicamente estratificados internamente. Como por exemplo onde a mulher é vista como objeto de desejo e do conhecimento do homem. Isto sugere uma situação em que formas de diferença passam a se substituir, e as distinções codificadas entre elas se tornam o lugar principal de produção de efeitos mais gerais de poder (MOORE, 2000).

Isto porque segundo (GROSZ, 2000), o pensamento misógino frequentemente encontra auto-justificativa conveniente para a posição social secundária das mulheres ao contê-las no interior de corpos que são representados, até construídos, como frágeis, imperfeitos, desregrados, não confiáveis, sujeitos a várias intrusões que estão fora do controle consciente.

A variável patriarcado tem um peso grande nesse cenário, no qual atribui a sexualidade feminina e os poderes de reprodução, tornando elas vulneráveis e necessitando de proteção ou de um tratamento especial. Desta feita definindo papéis sociais e económicas das mulheres a termos biológico.

$\mathrm{O}$ que de certa forma acaba formando uma série de atributos sociais referente a cada categoria: homem, mulher.

Na marcha uma série dessas dimensões foi reivindicada pela mulherada.

"Roupas curtas não estupram. Horários não estupram.Lugares não estupram. Bebidas não estupram. Estupradores estupram”. Isto porque uma série de categorias sociais acabam determinando nesse caso as roupas que as mulheres usam, os horários para estarem nas ruas, os lugares que devem frequentar e que não deve, consumir bebidas alcoólicas porque caso contrário correriam riscos. Estes estereótipos são construídos e enraizados na sociedade.

A hostilidade do pensamento misógino em relação as mulheres e à feminilidade foi comummente racionalizada através da depreciação e derrisão dos corpos das mulheres (GROSZ, 2000). Isto acaba gerando hostilidade. 


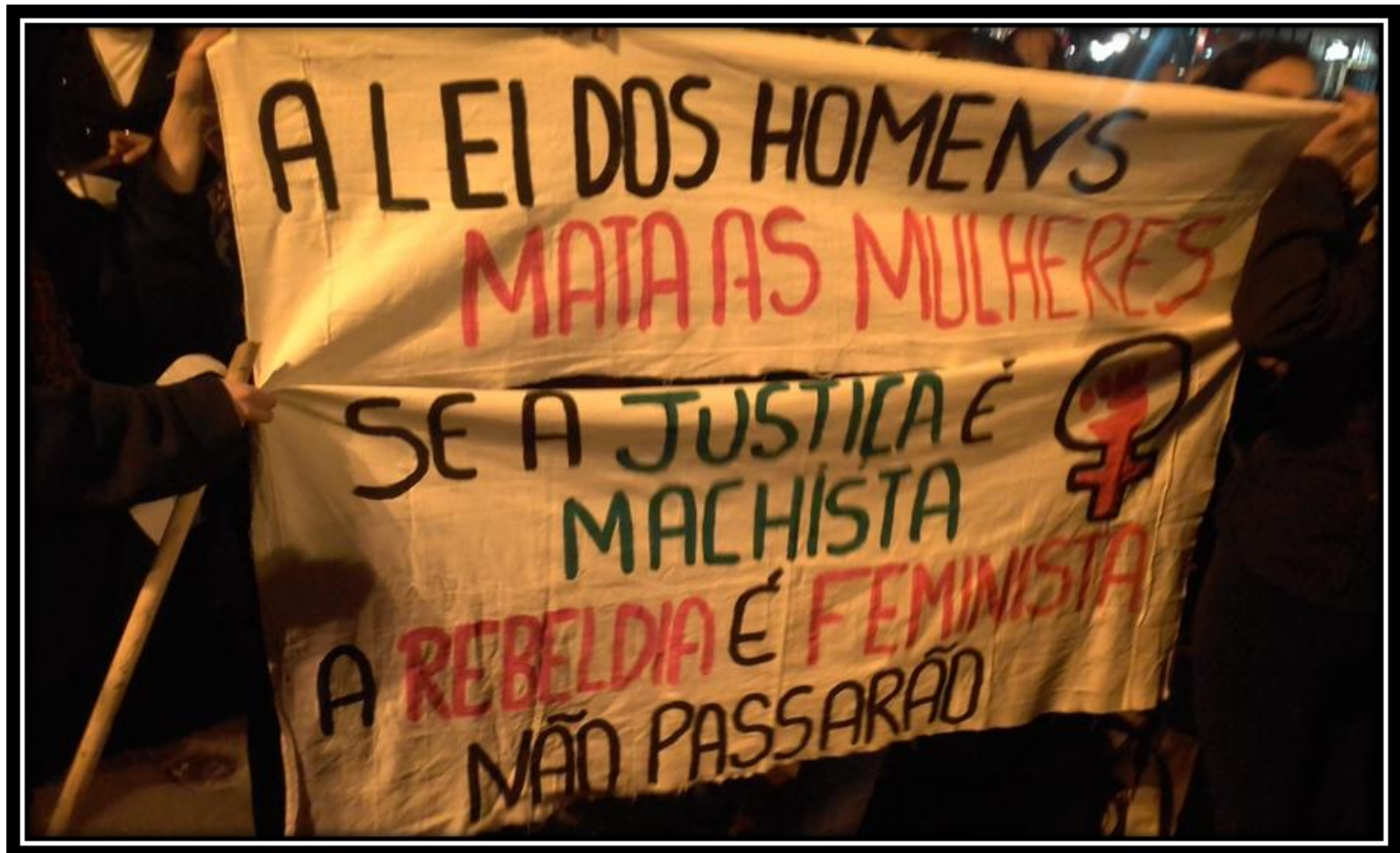

Figura 2: Palavras de ordem proferida na marcha. Fonte: da autora, Junho de 2016.

“Nem recatada, e nem do lar, a mulherada 'tá' na rua pra lutar". Foram cantadas também "Cadê o homem que engravidou? Por que a culpa é da mulher que abortou?", "Mexeu com uma, mexeu com todas" e "Se cuida, seu machista, a América Latina vai ser toda feminista" (Palavras proferidas nas marcha, 1 de Junhos de 2016).

\section{A QUESTÃO DA INTERCIONALIDADE: RAÇA E GÉNERO}

A interseção, defendida sobretudo pelas feministas negras a partir de 1980, tornou-se uma ferramenta teórica e metodológica fundamental para as ativistas e teóricas feministas negras que desenvolvem análises sobre os processos de interação entre ralação de poder e categorias como raça e género.

Num contexto onde as questões raciais e de género fundamentam essa opressão, que recai não só nos corpos, mais nos reflexos da própria sociedade. A intercecionalidade propõe na justa medida perceber o quanto os dois conceitos não estão separados e consequentemente não devem ser tratados como tal. A intercionalidade permite-nos ver os problemas sociais que estão estruturalmente na sociedade onde se vê os seus reflexos no quotidiano. E o caso da marcha acabou por evidenciar esta questão, pois a mesma constitui-se como um reforço para reivindicação de um problema que vira e mexe aparece nos mídias, mas, mais do isso, há que 
conviver com isso. O corpo é fortemente tido como um demarcador da problemática que é muito mais complexo, remetendo-nos para o contexto colonial.

Para aquelas meninas da marcha, a questão de género evidencia experiências e ideias que ofereceram visão de ser mulher, da comunidade ou seja é uma visão total que envolve compreensão da realidade pelas quais elas vivem. A interseção de género e raça tenta dar conta do tipo de opressão que as mulheres negras têm sofrido.

Como realçou (SILVA, 2016. p:52) na sua pesquisa "o género para as mulheres negras normalmente está vinculado ao sexismo, mas na realidade vai além, pois o feminismo posicionou os papéis de género como construídos socialmente, independente de qualquer base biológico".

Isto porque as mulheres negras constroem a questão de género com a importante articulação política. Pois no contexto da marcha denominada por todas elas, tinha essa brecha. Porém a invisibilidade se fazia presente.

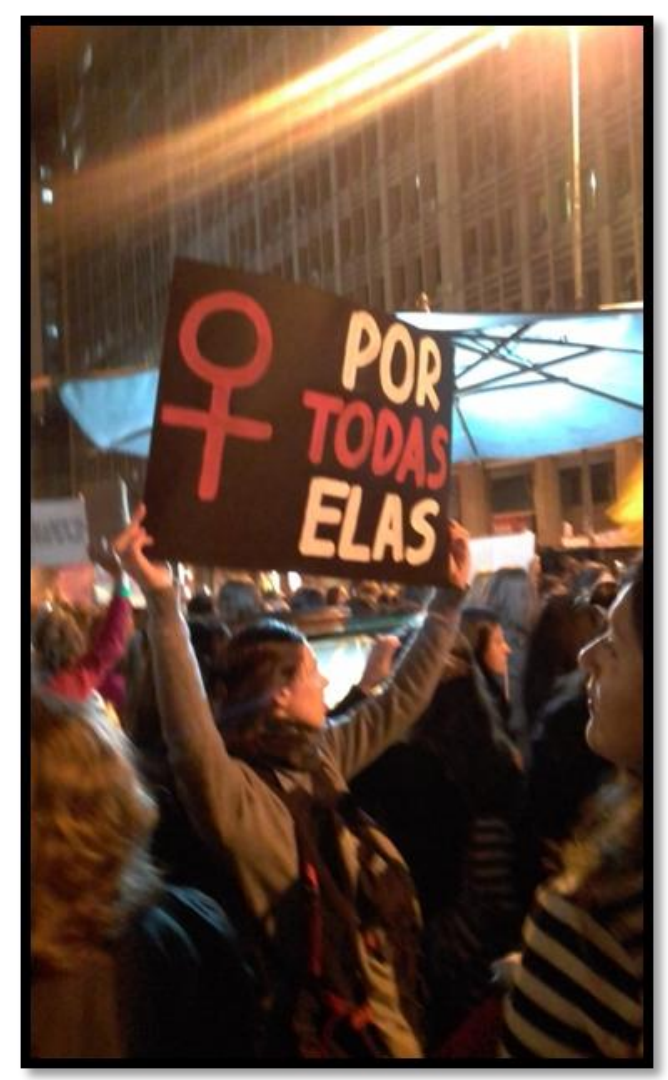

Figura 3 - Por todas elas! Fonte: da autora, Junho de 2016.

A questão de raça normalmente se sobressai à questão de género quando se trata de mulheres negras. Mas quando trabalha com uma perspetiva de intercionalidadea categoria de 
género e raça se agrupa. Permitindo assim, a oportunidade de entender a complexidade da vida das mulheres negras.

\section{CONSIDERAÇÕES FINAIS}

Roupas curtas não estupram. Horários não estupram. Lugares não estupram. Bebidas não estupram. Estupradores estupram" (Palavras proferidas na Marcha de 1 de Junho de 2016 em Porto Alegre - Brasil).

As questões específicas das mulheres negras, que além do machismo sofrem com o racismo, também foram mencionadas. Como a Reginete Bispo, coordenadora da organização de Mulheres Negras Akanni, lembrou que os dois preconceitos existem a partir da "ideia de dominação dos corpos”, que está naturalizada em nossa sociedade é o que permite que aconteçam crimes como o estupro e vários casos de violência contra a mulher.

Pois a necessidade da interseção entre a categoria de género e raça se torna fundamental para fazer frente a demanda social. E como foi proferido na marcha, "a nossa luta é todos os dias, somos mulheres e não mercadoria".

Pois a cor da pele deixou de ser biológico para ser uma questão étnica, onde consequentemente acabou por se naturalizar o étnico e configurou o biológico. Há que pensarmos que explica a diversidade é a cultura e não raça.

\section{REFERÊNCIAS}

BOURDIEU, Pierre 1999, A Dominação Masculina. Oeiras: Celta.

BUTLER, Judith. 2003. Problemas de gênero: feminismo e subversão da identidade. Rio de Janeiro: Civilização brasileira, (cap. 1).

SILVA. Daiane da. 2016. Gênero, raça e classe: discurso de mulheres negras académicas e mulheres negras comunitárias. Dissertação de mestrado apresentado ao Programa de Pósgraduação em Ciências Sociais na Universidade do Vale do Rio dos Sinos. São Leopoldo RS.

GROSZ. Elizabeth. Corpos reconfigurados. In PISCITELLI.A e GREGORI. M (14). Cadernu Pagu. 2000. PP:45-86.

HARAWAY, Donna. 1995. Saberes localizados. Cadernos Pagu, v. 5, p. 11-41,

MOORE, L. Henrietta. 2000. Fantasias de pobre e fantasia de identidade: género, raça e Violência. In PISCITELLI.A e GREGORI. M (14). Cadernu Pagu.. PP: 13-44. 
PISCITELLI, Adriana. 2008. Interseccionalidades, categorias de articulação e experiências de migrantes brasileiras. Sociedade e Cultura, v. 11, n. 2, p. 263-274, jul/dez.

SPIVAK, C. Gayatri. 2010. Pode o Subalterno Falar? Tradução de Sandra Regina Almeida, Marcos Pereira Feitosa, André Pereira Feitosa - Belo Horizonte: Editora UFMG.

STRATHERN, Marilyn. O efeito etnográfico. In: O efeito etnográfico e outros ensaios. São Paulo: CosacNaify, 2014, p. 345- 405. 